\title{
Knowledge and awareness of cervical cancer, its prevention and attitude towards human papillomavirus vaccine among medical students
}

\author{
Jenitha B. ${ }^{1 *}$, Subbiah M. ${ }^{2}$, Revwathy S. $^{1}$
}

\author{
${ }^{1}$ Department of Obstetrics and Gynecology, Trichy SRM Medical College Hospital and Research Centre, Irungalur, \\ Trichy, Tamil Nadu, India \\ ${ }^{2}$ Consultant, Pediatrician, Trichy, Tamil Nadu, India
}

Received: 19 November 2019

Revised: 04 December 2019

Accepted: 30 December 2019

\section{*Correspondence:}

Dr. Jenitha B,

E-mail: drbjenitha@gmail.com

Copyright: (C) the author(s), publisher and licensee Medip Academy. This is an open-access article distributed under the terms of the Creative Commons Attribution Non-Commercial License, which permits unrestricted non-commercial use, distribution, and reproduction in any medium, provided the original work is properly cited.

\begin{abstract}
Background: Cervical cancer is still one of the most common cancers affecting females in India, leading to a lot of mortality and morbidity. The objective of this study was to assess the awareness of the human papillomavirus (HPV) infections and vaccination among the medical students of a tertiary care teaching hospital.

Methods: A total 300 final year I and II medical students were requested to complete a questionnaire regarding cervical cancer, primary and secondary preventive measures and attitude of students towards HPV vaccination and the answers were then analysed.

Results: Among 300 medical students, $46.6 \%$ were males and $53.4 \%$ were females. Most of them were aware of the common risk factors like early marriage (92.7\%), multiple partners (99\%), multiparity (83.3\%) and HPV exposure $(85.7 \%)$. Most were aware of the cervical cancer symptoms like offensive vaginal discharge (70\%), irregular vaginal bleeding $(92.7 \%)$ and postcoital bleeding $(80.3 \%) .90 \%$ were aware that cervical cancer is preventable and $74 \%$ were aware that vaccine is available in India. $70 \%$ were aware about the best age to vaccinate is $9-13$ years. About $10 \%$ were already vaccinated and all were females. Out of 270 students who have not administered HPV vaccine, $53.4 \%$ didn't take the vaccine because of lack of awareness. High cost (18.8\%), fear of side effects (13.8\%) and doubt on efficacy $(14 \%)$ were the other reasons reported for non-administration of vaccines.

Conclusions: The study showed that there were gaps in knowledge regarding HPV infection and vaccination existed amongst the medical students. So, awareness among the students should be created and a more integrated teaching regarding various aspects of HPV infection, cervical cancers and its prevention needs to be introduced in the medical education system.
\end{abstract}

Keywords: Attitude, Awareness, Cervical cancer, Human papilloma virus infection, Human papilloma virus vaccine

\section{INTRODUCTION}

Cervical cancer is the second most common cancer among women worldwide and a major health problem in India and accounts for $26.1-43.8 \%$ of all cancers in Indian women. ${ }^{1,2}$
About 500,000 women are diagnosed with cervical cancer contributing to around 270,000 deaths, across the globe every year. Out of these, the burden of 230,000 $(85 \%)$ deaths is owned by developing countries, with bare minimal resources to cope with the situation. ${ }^{3}$ In India alone there are an estimated 132,000 new cases and 
74,000 deaths each year. ${ }^{4}$ The discovery that human papillomavirus (HPV) is responsible for virtually all cervical cancers opens exciting new possibilities for controlling this disease..$^{5-7}$ Lack of knowledge about cervical cancer in the population and among health care workers is a prime barrier for access to cervical cancer prevention. It is crucial that Indian medical students should be aware of the advances and especially of those interventions, which can be utilized, in low-resource settings. As preventing cancer with the help of a vaccine is a comparatively new concept, awareness and education will have important implication in the implementation of this strategy. Medical students were chosen for the simple reason that in a few years these students will be the practicing clinicians, and will be sought by the population as the first line information resources and can play a pivotal role in spreading awareness among a wide range of population. Educational initiatives targeting health care professionals have a definitive role in fostering vaccine acceptance. As demonstrated by Gonik et al educational interventions can positively influence immunization-related practice patterns. $^{8}$ So, authors conducted this study to assess the knowledge and attitude of the medical students who are the best persons to disseminate the information of HPV and HPV vaccinations.

\section{METHODS}

This study is a cross-sectional study that was conducted in the department of obstetrics and gynecology, Trichy SRM Medical College Hospital and Research Centre, Trichy. The study period was from July 2019 to September 2019. Three hundred medical students of final year part I and part II of this institute were recruited for the study. The only exclusion criterion was unwillingness of the student to participate in the study. Students were introduced to the study by a consultant gynecologist and were encouraged to participate in the study. Students were allowed to ask questions regarding their participation, were provided with a written summary of information about the study. Written consent for participation was obtained which was collected separately after it had been signed by the participant in order to avoid personal identification. A preformed structured questionnaire regarding the knowledge of cervical cancer, its risk factors, preventive measures, HPV vaccine, and screening tests was prepared and the validity of the questionnaire was done in a pilot study among the interns and junior residents. Then the validated questionnaire was given to the students. They were asked to fill the questionnaire and return back in the same session. The personal information and confidentiality of the student was guaranteed.

\section{Statistical analysis}

The results were analysed by statistical package for the social sciences software version 16. This study was approved by the Institutional Ethics Committee.

\section{RESULTS}

The study sample consisted of 300 medical students, belonging to final year part 1 and 2 . Their age ranged between 20-23 years and the mean age was 21.4. All of them were unmarried. Males formed $(\mathrm{N}=140) 46.6 \%$ of study population and females $(\mathrm{N}=160) 53.4 \%$.

Among 300 students $278(92.7 \%)$ were aware that early marriage is a risk factor. 297 (99\%) students and 250 $(83.3 \%)$ students knew that multiple partners and multiparity are risk factors for carcinoma cervix respectively. $257(85.7 \%)$ students knew that HPV exposure is one of the common risk factors. However, $207(69 \%)$ students felt that human immunodeficiency virus (HIV) infection did not have any role to play in the etiology of cervical cancer. 189 (63\%) students felt that usage of condom reduces the risk of cervical cancer. Out of 300 students, $240(80 \%)$ were not aware that early stages of carcinoma cervix might be asymptomatic but $70 \%$ were aware of the fact that it most commonly presents with offensive vaginal discharge and $92.7 \%$ were aware that it might present with irregular vaginal bleeding. $241(80.3 \%)$ students were aware that post coital bleeding is one of the common symptoms (Table $1)$.

Table 1: Knowledge regarding risk factors and clinical features of cervical cancer.

\begin{tabular}{|lll|}
\hline Questions & Yes $(\%)$ & No $(\%)$ \\
\hline Risk factors & & \\
\hline Early marriage & $278(92.7)$ & $22(7.3)$ \\
\hline Multiple partners & $297(99)$ & $3(1)$ \\
\hline Multiparity & $250(83.3)$ & $50(16.7)$ \\
\hline HPV exposure & $257(85.7)$ & $43(14.3)$ \\
\hline HIV infection & $93(31)$ & $207(69)$ \\
\hline Usage of condom & $111(37)$ & $189(63)$ \\
\hline Symptoms & & \\
\hline Asymptomatic & $60(20)$ & $240(80)$ \\
\hline Vaginal discharge & $210(70)$ & $90(30)$ \\
\hline Post coital bleeding & $241(80.3)$ & $59(19.7)$ \\
\hline $\begin{array}{l}\text { Menorrhagia/ } \\
\text { Metorrhagia }\end{array}$ & $278(92.7)$ & $22(7.3)$ \\
\hline
\end{tabular}

Among 300 students 270 (90\%) were aware that cervical cancer is preventable. $202(74 \%)$ students were aware that vaccine is available in India. Only $80(26.6 \%)$ students knew that it is not $100 \%$ effective in preventing carcinoma cervix. 210 (70\%) students were aware about the best age to vaccinate is $9-13$ years, whereas only $16 \%$ were aware that the vaccine can be given up to the age of 45 years. $265(88.4 \%)$ students didn't know that the vaccine can be given to boys.

Only $72(24 \%)$ students were aware that the vaccine can be given to sexually active women. 178 (59.3\%) students answered screening for HPV is a prerequisite for vaccination (Table 2 ). 
Table 2: Knowledge regarding HPV vaccine.

\begin{tabular}{|lll|}
\hline Questions & Yes $(\%)$ & No (\%) \\
\hline Can cervical cancer be prevented by a vaccine? & $270(90)$ & $30(10)$ \\
\hline Is vaccine available in India? & $202(74)$ & $68(26)$ \\
\hline Does it guarantee 100\% protection from cervical cancer? & $80(26.6)$ & $220(73.4)$ \\
\hline The best time to vaccinate is between 9-13 years of age & $210(70)$ & $90(30)$ \\
\hline It can be given until age 45 & $48(16)$ & $252(84)$ \\
\hline Can it be given to boys? & $35(11.6)$ & $265(88.4)$ \\
\hline Can it be given to sexually active girls? & $72(24)$ & $228(76)$ \\
\hline Screening for HPV is a prerequisite for vaccination & $178(59.3)$ & $122(40.7)$ \\
\hline
\end{tabular}

Table 3: Knowledge about secondary prevention.

\begin{tabular}{|lll|}
\hline Questions & Yes (\%) & No (\%) \\
\hline Is Pap smear the commonest method used to screen for cancer cervix in India? & $282(94)$ & $18(6)$ \\
\hline Is it 100\%Effective in diagnosing cervical cancer? & $256(85.3)$ & $44(14.7)$ \\
\hline Is there role for conservative treatment after detecting dysplasia? & $150(50)$ & $150(50)$ \\
\hline Do patients need follow up after conservative procedure? & $64(21.3)$ & $236(78.7)$ \\
\hline
\end{tabular}

Table 4: Attitude towards vaccination.

\begin{tabular}{|lll|}
\hline Questions & Yes $(\%)$ & No $(\%)$ \\
\hline Does the vaccine prevent all cervical cancer? & $66(22)$ & $234(78)$ \\
\hline Does the vaccine prevent other cancers also? & $30(10)$ & $270(90)$ \\
\hline Does the vaccine prevent STD? & $242(80.67)$ & $58(19.33)$ \\
\hline Can the vaccine be given to already HPV positive women? & $38(12.7)$ & $262(87.3)$ \\
\hline Do vaccinated women become HPV positive? & $225(75)$ & $75(25)$ \\
\hline Do vaccinated women require screening? & $95(31.7)$ & $205(68.3)$ \\
\hline Have you vaccinated with HPV vaccine? & $30(10)$ & $270(90)$ \\
\hline Will you give consent for vaccination against HPV? & $122(40.6)$ & $178(59.4)$ \\
\hline
\end{tabular}

Most of the students $282(94 \%)$ knew that Pap smear is the commonest test used to screen carcinoma cervix. 256 $(85.6 \%)$ students were of the false belief that screening methods are $100 \%$ effective in preventing carcinoma cervix. Only $150(50 \%)$ students were aware that uterus can be conserved even after detecting dysplasia. But 236 (78.7\%) students did not know that follow up screening procedures are needed after conservative procedures (Table 3).

A total $234(78 \%)$ students were aware that vaccine is will not prevent all cervical carcinoma but only $30(10 \%)$ students knew that it is effective in preventing other cancers also. Only $38(12.7 \%)$ students were aware that vaccination can be given to already HPV positive women and $262(87.3 \%)$ students were not aware that the vaccine can be given to women already having HPV infection. About $75 \%$ students falsely believed that they will become HPV positive after vaccination and only 95 $(31.7 \%)$ students were aware that vaccinated women also require screening. About $30(10 \%)$ students were already vaccinated. All were females. Of the remaining students only $122(40.6 \%)$ were willing to get vaccinated. 178 $(59.4 \%)$ were not willing to get vaccinated (Table 4$)$.
Out of 270 students who have not administered HPV vaccine, I44 (53.4\%) students didn't take vaccine because of lack of awareness. High cost (18.8\%), fear of side effects $(13.8 \%)$ and doubt on efficacy (14\%) were the other reasons reported for non-administration of vaccines (Table 5).

Table 5: Reasons reported for non-administration of vaccines.

\begin{tabular}{|ll|}
\hline Reason & $\mathbf{N}=\mathbf{2 7 0}$ (percentage of students) \\
\hline Lack of awareness & $144(53.4 \%)$ \\
\hline High cost & $51(18.8 \%)$ \\
\hline Fear of side effects & $37(13.8 \%)$ \\
\hline Doubt on efficacy & $38(14 \%)$ \\
\hline
\end{tabular}

\section{DISCUSSION}

The world pattern of cervical cancer indicates that this is predominantly a problem of low-resource-setting countries. The main reason is limited access to screening and treatment facilities. The HPV vaccination alone or combined with screening for carcinoma cervix has been documented as effective interventions in reducing the 
burden and mortality due to cervical cancer across various settings.

In our study $270(90 \%)$ students were aware that cervical cancer is preventable and $202(74 \%)$ were aware that vaccine is available in India. Pandey et al studied awareness and attitude toward HPV vaccine among 618 medical students in India and found that majority of participants $(89.6 \%)$ were well aware of the preventable nature of cervical cancer. ${ }^{9}$ Most of them $(89.2 \%)$ knew that necessary factor responsible for cervical cancer is infection with high-risk HPV. Awareness regarding the availability of vaccine against cervical cancer was $75.6 \%$. A study conducted by Saha et al, in Kolkata, India revealed a very low level of awareness among the graduate and postgraduate students about this important public health issue. ${ }^{10}$

In the present study, only $80(26.6 \%)$ students knew that vaccine is not $100 \%$ effective in preventing carcinoma cervix. $210(70 \%)$ students were aware about the best age to vaccinate is $9-13$ years, whereas only $16 \%$ were aware that the vaccine can be given up to the age of 45 years. $265(88.4 \%)$ students didn't know that the vaccine can be given to boys. Only $72(24 \%)$ students were aware that the vaccine can be given to sexually active women. 178 (59.3\%) students answered screening for HPV is a prerequisite for vaccination.

In a similar study conducted by Rathod S et al $34.9 \%$ students were aware that it does not give $100 \%$ protection from cervical cancer, but majority were not sure about the efficacy of the vaccine. ${ }^{11}$ Majority of the students had a wrong conception that vaccine was given in 30 to 50 years age group and they were not sure about the number of doses of vaccine to be taken; $51 \%$ felt that boys need not take the vaccine, whereas $29.8 \%$ had no idea whether boys could take the vaccine. A total of $68.12 \%$ students were aware that it could be given to a sexually active girl, but there was a misconception that screening for HPV was mandatory prior to vaccination $(56.38 \%)$ and that it could not be given to those already having HPV infection (59\%).

In our study $240(80 \%)$ students were not aware that early stages of carcinoma cervix might be asymptomatic but majority of students were aware of symptoms related to cervical cancer like offensive vaginal discharge (70\%), irregular vaginal bleeding $(92.7 \%)$ menstrual disturbances and postcoital bleeding (80.3\%). $63 \%$ students felt that condoms decreased the risk of cervical cancer. Most of the students 282 (94\%) in the present study knew that Pap smear is the commonest test used to screen carcinoma cervix. $256(85.6 \%)$ students were of the false belief that screening methods are $100 \%$ effective in preventing carcinoma cervix.

In the study conducted by Rathod $\mathrm{S}$ et al, majority of students were aware of symptoms related to cervical cancer like menstrual disturbances, postcoital bleed, smelly or blood-stained vaginal discharge and fever. ${ }^{11}$ However, $59.73 \%$ of students felt that cervical cancer may not be present in asymptomatic people. Majority of students $(96.64 \%)$ were aware that Pap smear was used to screen for cervical cancer.193 (64.7\%) students thought that it was $100 \%$ effective in screening for cervical cancer. When it came to undergoing the test themselves or their female family members, opinion was divided, with only $57.72 \%$ opting to go for it.

In the present study only $30(10 \%)$ students were vaccinated. All were females. Of the remaining students only $122(40.6 \%)$ were willing to get vaccinated. 178 (59.4\%) were not willing to get vaccinated. Among 270 students who were not administered HPV vaccine, the most commonly quoted reason for not administering these vaccines was lack of awareness (53.4\%). High cost (18.8\%), fear of side effects $(13.8 \%)$ and doubt on efficacy $(14 \%)$ are the other reasons reported for nonadministration of vaccines.

In a similar study conducted by Tripathy $S$ et al about $4.1 \%$ of the students have been vaccinated against HPV and $95.9 \%$ were not vaccinated prior to this study. ${ }^{12}$ But only $36.1 \%$ of students were ready to give consent for vaccination as compared to $63.9 \%$ of students who were not willing for vaccination. Majority of students (68.9\%) said that there is no need of routine vaccination of young Indian population as the sexual exposure occurs at late stage of the life and the age of vaccination should be $>25$ year as answered by $73 \%$ students. But $31.1 \%$ students felt that there is a need for routine vaccination to young population due to rapid urbanization and changes in culture.

In the study done by Pandey et al, overall acceptance of HPV vaccine among the population studied was $67.8 \% .^{9}$ Females seemed to be more ready to accept the vaccine and recommend it to others. Majority of participants agreed that the most important obstacle in implementation of HPV vaccination program in our country is inadequate information and $86.2 \%$ wanted to be educated by experts in this regard. Overall, a higher level of awareness was found among female subjects than male subjects, and this is consistent with the findings observed by Mehta $\mathrm{S}$ et al. ${ }^{11}$ Pandey et al, also reported high cost $(21.2 \%)$, fear of complications (17.6\%) and worry about efficacy $(16.7 \%)$ are the important obstacles for implementation of HPV vaccination program. However more than half $(56.7 \%)$ agreed that most important problem is inadequate information. Studies from China and Turkey too found high monetary cost, as the most important perceived barrier for implementation of HPV vaccine in their population. ${ }^{13,14}$ In another study, Guducu et al, studied the knowledge of nurses and students of İstanbul Bilim University and affiliated hospitals about HPV and cervical cancer and found that only $52 \%$ accepted to get a daughter vaccinated. ${ }^{15}$ The main reasons for vaccine rejection were the concerns about vaccine safety $(41 \%)$, cost of the vaccine $(10 \%)$, 
and sexual promiscuity (5\%) after vaccination. Mehta S et al reported that $66.8 \%$ were willing to accept the HPV vaccine. ${ }^{15}$ Females were more willing to accept vaccination. Majority of students said that lack of adequate knowledge was the most important factor preventing them from getting vaccinated. This is consistent with several other studies in India, another main reason being high cost.

\section{CONCLUSION}

HPV vaccine for primary prevention of cervical cancer is a relatively new concept. This concept will be amalgamated in practice only with its increased understanding by the provider and the recipient. Health professional will be able to play a pivotal role in popularizing this strategy. Our academic curriculum in the medical schools needs to focus more on such high priority practical upcoming issues. Better understanding of the major preventive public health issues by health care professionals will definitely be propagated well in the society. All medical students (today) will not be educators in medical schools, but they are the trustworthy sources to the society full of information in this internet era.

It is necessary to implement health education programs, group discussions and forums where aspects of HPV infection, its association with cervical cancer, and the HPV vaccine are clearly highlighted and doubts clarified. Clearing certain myths and misconceptions at student level will help in better implementation of health programs in the society.

\section{Funding: No funding sources}

Conflict of interest: None declared

Ethical approval: The study was approved by the Institutional Ethics Committee

\section{REFERENCES}

1. Cervical cancer control in developing countries: Memorandum from a WHO meeting. Bulletin World Health Organ. 1996;74:345-51.

2. Parkin DM, Bray F, Ferlay J. Estimating the world cancer burden: Globocan 2000. Int J Cancer. 2001;94:153-6.

3. Parkin DM, Bray F, Ferlay J, Pisani P. Global cancer statistics, 2002. CA Cancer J Clin. 2005;55:74-108.

4. Laikangbam P, Sengupta S, Bhattacharya P, Duttagupta C, Dhabali Singh T, et al. A comparative profile of the prevalence and age distribution of human papillomavirus type 16/18 infections among three states of India with focus on Northeast India. Int J Gynecol Cancer. 2007;17:107-17.
5. Walboomers JM, Jacobs MV, Manos MM, Bosch FX, Kummer JA, et al. Human papillomavirus is a necessary cause of invasive cervical cancer worldwide. J Pathol. 1999;189(1):12-9.

6. Bosch FX, Lorincz A, Munoz N, Meijer CJ, Shah KV. The causal relation between human papillomavirus and cervical cancer. J Clin Pathol. 2002;55(4):244-65.

7. Munoz N, Bosch FX, de Sanjose S, Herrero R, Castellsague X. Epidemiologic classification of human papillomavirus types associated with cervical cancer. $\mathrm{N}$ Engl J Med. 2003;348(6):518-27.

8. Gonik B, Jones T, Fasano N, Contreras D, Roberts C. Vaccine preventable diseases (VPD): improving the obstetrician/gynecologist's knowledge and immunization practice patterns. Am J Obstet Gynecol. 2001;185:S162.

9. Pandey D, Vanya V, Bhagat S, Binu VS, Shetty J. Awareness and attitude towards human papilloma virus (HPV) vaccine among medical students in a Premier Medical School in India. PLoS One. 2012;7(7):e40616.

10. Saha A, Nag Chaudhury A, Bhowmik P, Chatterjee R. Awareness of cervical cancer among female students of premier colleges in Kolkata, India. Asian Pacific J Cancer Prevent. 2010;11:1085-90.

11. Rathod S, Samal SK, Samal S, Ghose S. Knowledge and awareness of cervical cancer and human papilloma virus vaccine among medical students: a cross-sectional study. J South Asian Federation Menopause Societies. 2017;5(1):41-4.

12. Tripathy S, Mohapatra S, Muthulakshmi M, Jamuna Rani R. Knowledge, attitude towards human papillomavirus and HPV vaccine among medical students of a tertiary care teaching hospital in India. Int J Reprod Contracept Obstet Gynecol. 2015;4(6):1771-4.

13. Kwan TT, Chan KK, Yip AM, Tam KF, Cheung AN, Lee PW, et al. Barriers and facilitators to human papillomavirus vaccination among Chinese adolescent girls in Hong Kong: a qualitative-quantitative study. Sex Transm Infect. 2008;84(3):227-32.

14. Baykal C, Al A, Ug ur MG, Cetinkaya N, Attar R, Arioglu P, et al. Knowledge and interest of Turkish women about cervical cancer and HPV vaccine. Eur J Gynaecol Oncol. 2008;29(1):76-9.

15. Guducu N, Gonenc G, Herman I, Yigiter AB, Dunder I. Awareness of human papilloma virus cervical cancer and HPV vaccine in healthcare workers and students of medical and nursing schools. J Clin Exp Invest. 2012;3(3):318-25.

Cite this article as: Jenitha B, Subbiah M, Revwathy $\mathrm{S}$. Knowledge and awareness of cervical cancer, its prevention and attitude towards human papillomavirus vaccine among medical students. Int $\mathbf{J}$ Reprod Contracept Obstet Gynecol 2020;9:613-7. 